\title{
The Research on Multimedia Assisted English Vocabulary Teaching Courseware: Design and Application
}

\author{
HAN Bing ${ }^{1, a}$ \\ ${ }^{1}$ Dezhou Vocational and Technical College, Dezhou 253034, China \\ a bingxia-002@163.com
}

Keywords: Multimedia Assistance; Teaching Courseware; English Words; Case Study.

\begin{abstract}
In this paper, we analysis the design and corresponding applications of multimedia assisted English words teaching courseware. Now more and more people are paying attention to the network teaching, especially some foreign universities and education web sites and taking the network courseware teaching which has received the good effect. There is a huge difference between general multimedia teaching courseware, multimedia teaching courseware based on multimedia technology, is refers to the general teaching software, is based on certain teaching target performance that reflects a specific teaching content, the teaching strategy of multimedia applications, it is the use of computer multimedia technology to text, graphics, sound, animation, and other media together to form. In the future, we plan to conduct more case studies to prove the effectiveness of the approach.
\end{abstract}

\section{Introduction}

The information technology level has been improved in a high speed since human being entered 21st century. The technologies of communication, internet and multimedia have penetrated all aspects of education. Working, studying, thinking and communicating styles of human being have been influenced by Infobahn in a striking speed. The mode of traditional teaching centered on classroom, textbook and teacher can't adapt to the demand of the development of information times. With the development of social information and the traditional blackboard writing teaching model has gradually become obsolete with the modern education technology to adapt to changing social needs and growth. The popularization of the computer to the field of education has brought a new mode of multimedia courseware assisted instruction, but with the rise of the network, network teaching has become the new trend of modern education technology development and the way of development, is to need the support of a large number of network courseware. Network courseware is the core of modern distance education component. There is a huge difference between general multimedia teaching courseware, multimedia teaching courseware based on multimedia technology, is refers to the general teaching software, is based on certain teaching target performance that reflects a specific teaching content, the teaching strategy of multimedia applications, it is the use of computer multimedia technology to text, graphics, sound, animation, and other media together to form. They are committing themselves to make network courseware and construct modern teaching mode of college English based on constructivism theory. Owing to its advantages of affording interactive learning environment of interface amity and visualized and intuitionistic characteristics, multimedia and internet technology, the new technology and method has been increasingly applied to the teaching actively in order to develop online multimedia courseware and realize online teaching [1-3].

The introduction of multimedia teaching means in teaching process with multimedia computer as the core of modern teaching tool and means of a new type of teaching mode. It created a new field of interest teaching, mainly through the text, graphics, images, animation, sound, video and interactive network and so on, to the students' sense to form a variety of stimulation, make the teaching content, lively stimulate students' learning enthusiasm, effectively break through the emphases and difficulties in the teaching, improve the learning efficiency. With the rapid popularization and the development of the Internet and modern multimedia technology is undergoing a revolution in the networked. Network courseware is the combination of multimedia technology and network technology, change 
the traditional classroom teaching of theoretical knowledge is partial, passive situation, form a kind of active, intuitive teaching way, make teachers and students to maximize enhance classroom participation, stimulate students' interests and hobbies from each aspect, further improve the quality of teaching, the modern network teaching contain text, images, animation, video, voice and other special effects, give people a lot of the imagination, a strong initiative, not only changed the way we learn and understand the problem, but also changed the way we spread information [4-6]. Therefore, in this paper, we analysis the design and corresponding applications of multimedia assisted English words teaching courseware in detail in the following sections.

\section{The Proposed Methodology}

The Multimedia Learning Cognitive Theory. Multimedia learning cognitive theory is a contemporary American education psychologist with a cognitive psychologist Richard e. Meyer in his book "the multimedia learning" is put forward, and through a lot of psychological experiments prove the validity and scientific theory. From real, dynamic video footage, students can see the theory of the formation, development and utilization, deepen their understanding of knowledge. In multimedia network courseware, we can put things traced dynamically change process, so it is more than just describe image, vivid, intuitive and easy to students leave deep imprint. English teaching, especially the words of the study is relatively dry. It is a teacher more voice or uses a tape recorder voice and the students to read it. This way is easy to produce fatigue which will produce bad influence to the teachers and students and network courseware will let renew the students' thinking and stimulate their interest. As the result, learning is not so boring. Multimedia learning cognitive theory of the three hypotheses:

- Limited capacity hypothesis. People during cognitive processing is the need to consume the cognitive resources, and cognitive resources is limited, so in each channel last machining information quantity is also limited.

- Using the network courseware, simple boring text into vivid and interesting graphics files, to make the students more interested in which can make excellent in the different stages of teaching, network courseware and the subject of the curriculum idea, step by step to guide students to learn.

- Dual channel assumption. Refers to people in the cognitive process of visual representation and auditory characterization of materials has a corresponding information processing channel.

Multimedia technology. The multimedia overall design are shown in figure 1 below, the whole system can be divided into four parts: content acquisition, production and management section (CMS), data service center, wireless networks and wireless devices. Content management part in charge of multimedia audio and video data recording, storage and management; Data service center is responsible for communicate with wireless terminals and receives a command Request terminal equipment, after processing to give Response; Wireless network provides the network transmission medium; Wireless terminal equipment work is through the wireless network environment and real-time interactive communication, data center and real-time processing in the wireless network for multimedia data. 


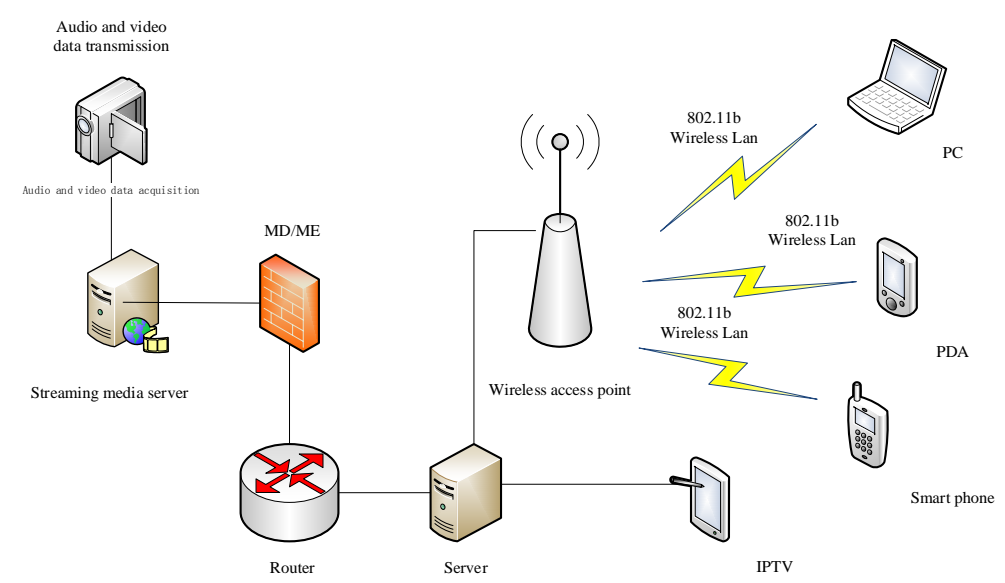

Figure 1. The architecture technology for multimedia and modern network

Interactive multimedia system for network interaction in the first place, doing the underlying transport interface definition, this paper shows how to use the underlying network communication protocol for data transmission; For the interpretation of the information transmission platform, illustrates the application of how messages transmitted the information transmission platform. Application platform need to provide services to meet the needs in the platform for secondary development, this article lists the three kinds of upper provide public services, to facilitate the management and development of application. An interactive multimedia network teaching system must have a specific application to complete the teaching process.

\section{The Use of Multimedia Teaching}

Now many vocational school attaches great importance to apply multimedia teaching and then not hesitate heavy gold, investment for the construction of the multimedia classroom, set up schools within the domain network, encourage teachers to make multimedia courseware. High quality, high efficiency of classroom teaching efficiency means the large capacity, high density and fast rhythm, it requires 45 minutes in the limited class teaching time, let the students fully grasp the teaching contents. In today's modern classroom teaching, the traditional a piece of chalk, a book, a book lessons this language teaching mode has far cannot satisfy the requirement of new curriculum in classroom teaching capacity. Following the introduction of English classroom teaching of multimedia courseware, the insufficient capacity of classroom teaching has been changed. Teachers using multimedia courseware in English teaching, not only the classroom teaching task well, and have enough time to add a lot of content related to the teaching goal, and combining the content to further supplement and analysis was carried out on the textbook knowledge, enhances the student to grasp of the course content, improve the students' classroom learning efficiency. The following figure shows the sample user interface of the proposed platform.

There is no doubt that proper use of multimedia teaching, really to have dictation of the traditional hand can't reach the effect of teaching. For example, multimedia teaching intuitive vivid, the characteristics of static to dynamic, to extend classroom boundaries of time and space, and can be a lot of students of the initiative of the senses such as vision, hearing and touch, resulting in a strong artistic appeal, and so on. There are a lot of people it is not clear, primary and secondary when designing network courseware can't catch the key, can't grasp well the characteristics of the course, so that make a lot of redundant information, or don't conform to the course features of courseware, so as to reduce the students' learning enthusiasm. Such as: by the engineering course should be derived from the teachers to use real-time network courseware design, computer and experimental classes should use interactive simulation model to carry on the design, but a lot of courseware and curriculum does not match. Network teaching flexibility is good, can satisfy the requirement of the educational personalized some, there is no limit of time and space, can update of knowledge, and knowledge dissemination way agile diversity, more easily accepted by the people; Network courseware widespread use of network resources, the sharing is good, no matter the developers, learners can 
share resources, managers, or others, all the people together to participate in problem solving, improve the efficiency, gain the knowledge; Network courseware autonomy is strong, changed the way in the past mainly teach passive, and save a lot of class time, more ask students to independent to finish. Some application of multimedia in the teaching material content is suitable for teaching, and some are not suitable for multimedia teaching.

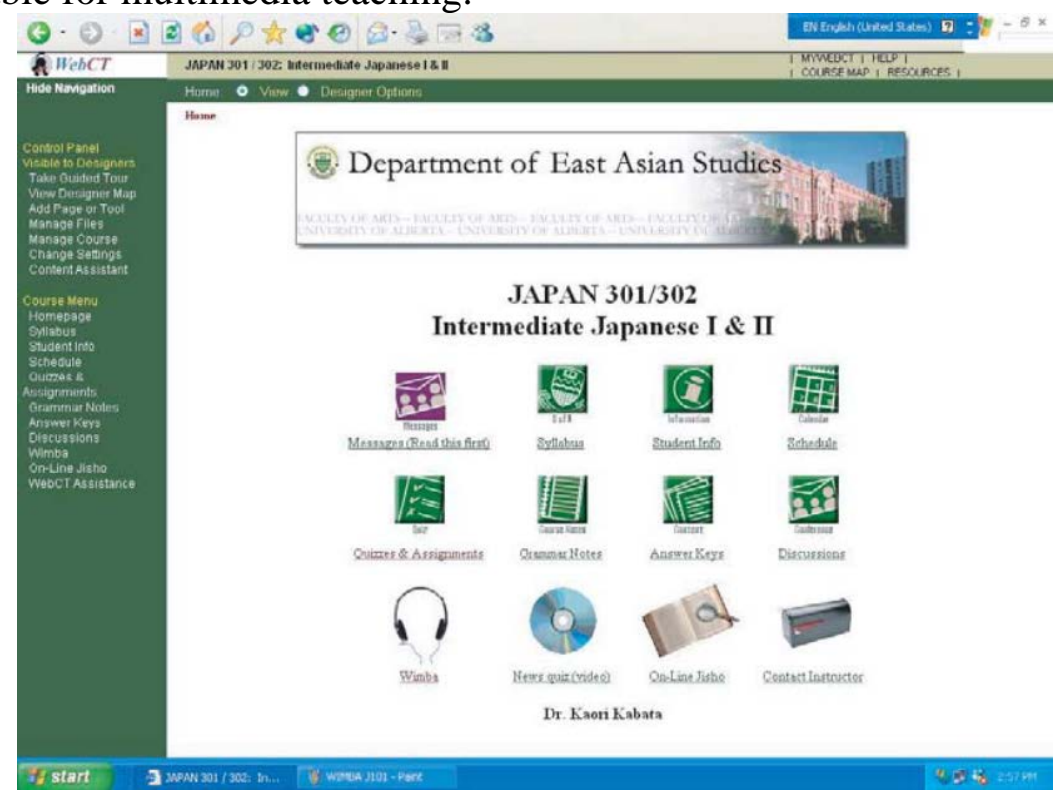

Figure 2. The Sample User Interface of the Platform

Using the Multimedia Teaching Can Improve Teaching Quality. Using multimedia teaching can improve teaching quality in a certain sense. Quality and efficiency is the eternal subject of education. By the quality of education is not only related to the success of education reform itself, or a relationship to the economic and social development of comprehensive and strategic issues. Improve the quality and efficiency of education, therefore, is not only the need of existence and development of education, as well as the objective need of talents training and social development. Multimedia courseware is the figure, the optimum combination of text, sound, like, to be able to provide students with a variety of sensory stimulation, so as to cultivate students' intuitive thinking and image thinking provides the basis. Education psychology thought, stimulate students' learning interest and thirst for knowledge can be inspired by creating problem situation, problems should be novel and interesting, and there are appropriate. Through the use of the multimedia courseware can achieve this goal. It provides a lot of pictures and sound, form and inertia, the activity of teaching material, make the boring classroom becomes lively, can also be created so that the students involved in the environment, students are no longer passive accept knowledge, but to actively participate in teaching activities. Diversified teaching material can cause the attention of students and further stimulate their interest, to mobilize students' learning initiative. Students actively participate in teaching activities, become passive to active, as the main body of learning, which can change the traditional teacher-centered teaching mode. The whole classroom teaching with the help of the multimedia courseware which can create a lively will provide interactive good classroom atmosphere. The making of multimedia courseware in teaching and film and television works, although can't rich artistic creativity, but also should have the same effect.

\section{Conclusion and Summary}

The information technology level has been improved in a high speed since human being entered 21st century. The technologies of communication, internet and multimedia have penetrated all aspects of education. In this paper, we analysis the design and corresponding applications of multimedia assisted English words teaching courseware. Now more and more people are paying attention to the network teaching, especially some foreign universities and education web sites and taking the 
network courseware teaching which has received the good effect. The mode of traditional teaching centered on classroom, textbook and teacher can't adapt to the demand of the development of information times. We firmly believe that the current teaching pattern will be largely structural polished and modified in the near future.

\section{References}

[1] Dong, X. (2014). Analysis on the problems and countermeasures of college multimedia assisted english teaching. Journal of Jiamusi Education Institute.

[2] *, J. H. L., Zhang, J., \& Jing, L. (2014). Formative assessments in junior high school english class based on multimedia-assisted language teaching. Machine Tool Technology Mechatronics \& Information Engineering.

[3] Yan-fang, Z. (2014). Study of dynamic stratified- teaching model in college english focus listening under multimedia technology environment. Journal of Anhui Science \& Technology University.

[4] Qingfang, S. (2014). The design of cai courseware system of sports and health course the application of multimedia technology assisted_—physical education teaching research series. Electronic Test.

[5] Lee, T. (2014). Using computer-assisted interpreter training methods in korean undergraduate english classrooms. Interpreter \& Translator Trainer, 8, 1, págs. 102-122.

[6] Hong, Z., Chen, Y., \& Lan, C. (2014). A courseware to script animated pedagogical agents in instructional material for elementary students in english education. Computer Assisted Language Learning, 27, 5, 379-394. 